\title{
Differences in Angiographic Profile and Immediate Outcome of Primary Percutaneous Coronary Intervention in Otherwise Risk-Free Young Male Smokers
}

Salik Ahmed ${ }^{1}$, Sanam Khowaja ${ }^{1}$, Saher Khowaja ${ }^{2}$, Tariq Ashraf ${ }^{3}$, Kanwal Aamir ${ }^{1}$, Mahesh K. Batra ${ }^{3}$, Musa Karim ${ }^{4}$, Muhammad Anis M. Ahmedani ${ }^{3}$, Syed Z. Jamal ${ }^{5}$

1. Adult Cardiology, National Institute of Cardiovascular Diseases, Karachi, PAK 2. Internal Medicine, Aga Khan University Hospital, Karachi, PAK 3. Cardiology, National Institute of Cardiovascular Diseases, Karachi, PAK 4. Statistics, National Institute of Cardiovascular Diseases, Karachi, PAK 5. Electrophysiology, National Institute of Cardiovascular Diseases, Karachi, PAK

Corresponding author: Salik Ahmed, salik.memon@hotmail.com

\section{Abstract \\ Introduction}

Cigarette smoking is a well-established risk factor for the development and progression of coronary artery disease (CAD) and it is strongly related to cardiac morbidity and mortality. Therefore, this study aimed to compare the angiographic profile and immediate clinical outcomes in young male smokers and non-smokers without any other cardiac risk factors presented with ST-elevation myocardial infarction (STEMI).

\section{Methods}

This study includes young ( $\leqslant 40$ years) male patients presented without cardiac risk factors other than smoking. Angiographic profile and immediate outcome of primary percutaneous coronary intervention (PCI) were collected from the hospital database.

\section{Results}

A total of 580 young male patients were included in this study, 51.2\% (297) were smokers. Baseline characteristics and presentation were similar for smoker and non-smoker groups. Angiographic profile was not significantly different for smokers in terms of pre-procedure thrombolysis in myocardial infarction (TIMI) flow ( $p=0.373)$, the number of vessels involved ( $p=0.813)$, infarct-related artery ( $p=0.834)$, and left ventricular dysfunction $(\mathrm{p}=0.311)$. Similarly, in-hospital outcomes of primary PCI were not significantly different in smokers. Post-procedure no-reflow was in $3.4 \%$ vs. $2.8 \%$; $=0.708$, acute stent thrombosis in $1.7 \%$ vs. $0.4 \% ; \mathrm{p}=0.114$ and in-hospital mortality in $1.0 \%$ vs. $1.4 \% ; \mathrm{p}=0.657$ of the smoker and non-smoker group, respectively.

Received 06/02/2020

Review began 06/13/2020 Review ended 06/18/2020 Published 06/24/2020

() Copyright 2020

Ahmed et al. This is an open access article distributed under the terms of the Creative Commons Attribution License CC-BY 4.0., which permits unrestricted use, distribution, and reproduction in any medium, provided the original author and source are credited.

\section{Conclusion}

Our study concludes smoking has no significant impact on the angiographic profile and immediate clinical outcomes of primary PCI after STEMI in young males, without any other conventional cardiac risk factors. With these findings, further multicenter prospective studies are needed to identify other potential causes in such patients.

Categories: Cardiology, Internal Medicine

Keywords: smoking, st-elevation myocardial infarction, young, angiography, primary percutaneous coronary intervention

\section{Introduction}

Asians are more than half of the world population and more than a quarter of the population of the developing world live in South Asian countries, namely, Pakistan, Bangladesh, India, Sri Lanka, Nepal, and Bhutan $[1,2]$. South Asian populations are known to have a higher tendency of coronary artery disease (CAD) and possess different genetic profiles and lifestyle than the western population [2]. Effective preventive measures for $\mathrm{CAD}$ in this population is crucial to curtailing the global disease burden. Identification and management of risk factors for CADs such as hypertension, hypercholesterolemia, diabetes, and smoking have proved to be effective preventive strategies in the western population [3]. In the last two decades, a transformation in dietary habits and lifestyle has been witnessed for the south Asian population due to urbanization and globalization of dietary behavior [3-6]. Such rapid transformation has led to an escalation of CAD in the region. 
According to the World Health Organization (WHO), global annual deaths attributable to cardiovascular diseases (CVD) are around 17.9 million, and more than $75 \%$ of these cases are from developing countries [7]. CADs are considered to be the disease of old age, unfortunately, the incidence of CAD is increased among the younger population $[8,9]$. A local study reported cigarette smoking as the second most prevalent CVD risk factor, after increased BMI, among young ( $<45$ years) patients [10]. A paradoxical phenomenon of favorable outcomes after acute myocardial infarction (AMI) was observed for smokers. In later studies, this phenomenon was attributed to the young age and lesser severe disease among smokers [11,12]. Smokers were found to develop ST-elevation myocardial infarction (STEMI) about 10 years earlier than non-smokers and smokers have higher sex- and age-adjusted one-year mortality [13].

Cigarette smoking is a well-established risk factor for the development and progression of coronary heart disease and is strongly related to morbidity and mortality and is a leading risk factor of CAD in our young population $[10,13]$. Data are scarce for the Pakistani population; therefore, this study aimed to compare the angiographic profile and immediate clinical outcomes in young male smokers and non-smokers without any other cardiac risk factor presented with STEMI and who underwent coronary intervention at a cardiac center in Karachi, Pakistan.

\section{Materials And Methods}

This retrospective observational study was conducted at the National Institute of Cardiovascular Diseases (NICVD) Karachi, Pakistan. The ethical review committee of the institute approved the study (ERC-33/2018) and in accordance with the Declaration of Helsinki, written informed consent was obtained from all patients regarding the procedure as well as the use of data for research purposes. Data for the study were extracted from the institutional primary percutaneous coronary intervention (PCI) database for the period from September 2015 to August 2018. As an institutional practice, demographics, presentation, diagnostic tests, and outcomes data were collected on pre-defined proforma, after patients consent, and anonymized data were available after institutional approval. In this study, we included young ( $<=40$ years) male patients who presented with STEMI and who undergone primary PCI. Patients with comorbid known risk factors of CAD, other than smoking, such as hypertension (HTN), diabetes mellitus (DM), family history of CAD, and dyslipidemia were excluded from the study. The patient selection criteria for the study were presented in Figure 1.

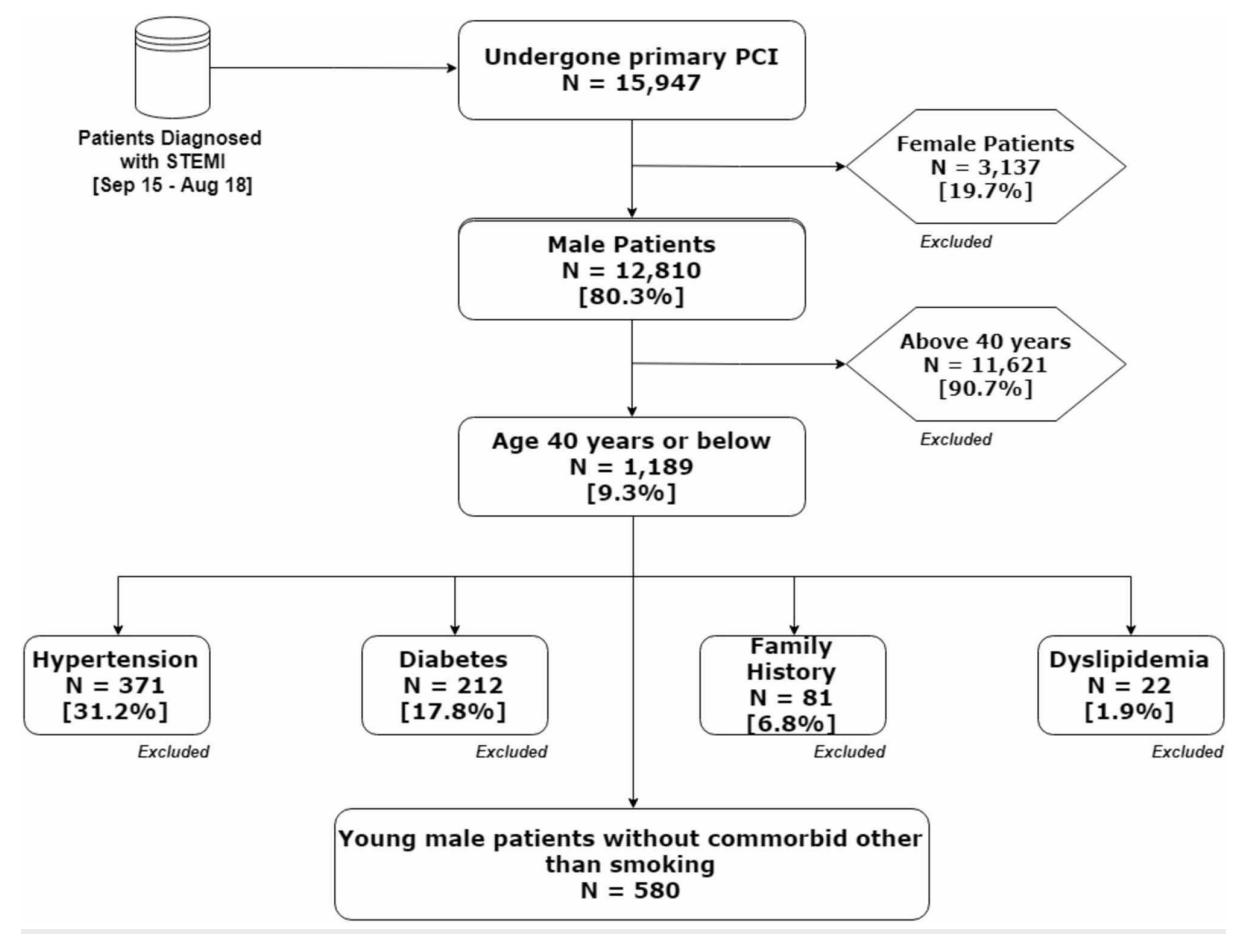

FIGURE 1: Patients selection criteria for the study

PCI, percutaneous coronary intervention; STEMI, ST-elevation myocardial infarction

The STEMI was defined and managed as per the ACCF/AHA STEMI diagnosis and management guidelines. As a routine assessment, angiography and primary PCI procedures were performed and interpreted by consultant cardiologists with the experience of five years or more. After routine workup, electrocardiographic (ECG) and cardiac enzyme assessment, clinical presentation (KILLIP class), symptom onset to hospital arrival time, and door to balloon time were recorded. Patients history regarding known risk 


\section{Cureus}

factors was obtained such as HTN (at least six months history of any antihypertensive medication), DM (at least six months history of any antihyperglycemic medication or insulin or glycated hemoglobin (HbA1c) > 6.5\%), dyslipidemia (low-density lipoprotein cholesterol (LDL-C) levels $>130 \mathrm{mg} / \mathrm{dL}$ and/or high-density lipoprotein cholesterol (HDL-C) levels $<40 \mathrm{mg} / \mathrm{dL}$ ), and family history (patient positive history of premature ischemic heart disease (IHD) in first degree relatives, male less than 55 years of age or female less than 65 years of age). Patients with a history of currently smoking five cigarettes a day for at least one year or equivalent were classified as smokers.

The angiographic profile of the patients was assessed in terms of chronic total occlusion (CTO), defined as thrombolysis in myocardial infarction (TIMI) flow grade 0 , the number of diseased vessels, infarct-related (culprit) artery, lesion complexity, involvement of side branch, left ventricular (LV) dysfunction, and thrombus grading. Intra and post-procedure, in-hospital, outcomes include procedure success (TIMI flow grade III), peri-procedural use of intra-aortic balloon pump (IABP) and export catheter, no-reflow (TIMI flow grade $0-\mathrm{I}$ ), acute stent thrombosis, and all-cause in-hospital mortality.

Patients were divided into two groups, smokers and non-smokers. Demographic profile, angiographic profile and immediate outcomes of primary PCI were compared in two groups. Statistical analyses of the extracted data were performed using IBM SPSS Statistics for Windows, Version 21.0 (IBM Corp., Armonk, NY). Mean ( ${ }^{ \pm}$ standard deviation) and percentage (frequency) were computed appropriately and the Mann-Whitney U test, for continuous variables, and chi-square test, for categorical variables, were performed. $\mathrm{P} \leqslant 0.05$ was taken as the level of significance.

\section{Results}

A total of 580 young male patients were included in this study, 51.2\% (297) were smokers. Smoker and nonsmoker groups were similar in terms of age $(35.29 \pm 4.59$ years vs. $35.54 \pm 4.49$ years, $\mathrm{p}=0.575)$, symptom onset to hospital arrival time $(238.87 \pm 230.00$ minutes vs. $239.19 \pm 187.83$ minutes, $\mathrm{p}=0.145)$, and door to balloon time $(80.35 \pm 49.30$ minutes vs. $83.78 \pm 71.6$ minutes, $\mathrm{p}=0.622)$. Comparison of baseline characteristics of smokers and non-smokers are presented in Table 1.

\begin{tabular}{|c|c|c|c|c|}
\hline Characteristics & Total & Smokers & Non-smokers & $\mathrm{p}$-value \\
\hline Total & 580 & $297(51.2 \%)$ & $283(48.8 \%)$ & - \\
\hline Age (years) & $35.41 \pm 4.54$ & $35.29 \pm 4.59$ & $35.54 \pm 4.49$ & 0.575 \\
\hline Body Mass Index (kg/m²) & $25.79 \pm 3.13$ & $25.88 \pm 3.58$ & $25.71 \pm 2.56$ & 0.78 \\
\hline \multicolumn{5}{|l|}{ KILLIP class } \\
\hline 1 & $533(91.9 \%)$ & $272(91.6 \%)$ & $261(92.2 \%)$ & \multirow{4}{*}{0.612} \\
\hline "I & $24(4.1 \%)$ & $15(5.1 \%)$ & $9(3.2 \%)$ & \\
\hline IIII & $11(1.9 \%)$ & $5(1.7 \%)$ & $6(2.1 \%)$ & \\
\hline IV & $12(2.1 \%)$ & $5(1.7 \%)$ & $7(2.5 \%)$ & \\
\hline \multicolumn{5}{|c|}{ Symptom onset to hospital arrival time } \\
\hline Mean \pm SD minutes & $239.18 \pm 210.3$ & $238.87 \pm 230$ & $239.5 \pm 187.83$ & 0.145 \\
\hline$\leq 120$ minutes & $202(34.8 \%)$ & $110(37 \%)$ & $92(32.5 \%)$ & \multirow{2}{*}{0.253} \\
\hline$>120$ minutes & $378(65.2 \%)$ & $187(63 \%)$ & $191(67.5 \%)$ & \\
\hline \multicolumn{5}{|l|}{ Door to balloon time } \\
\hline Mean \pm SD minutes & $82.02 \pm 61.18$ & $80.35 \pm 49.3$ & $83.78 \pm 71.6$ & 0.622 \\
\hline$\leq 90$ minutes & $429(74 \%)$ & $221(74.4 \%)$ & $208(73.5 \%)$ & \multirow{2}{*}{0.802} \\
\hline$>90$ minutes & $151(26 \%)$ & $76(25.6 \%)$ & $75(26.5 \%)$ & \\
\hline
\end{tabular}

\section{TABLE 1: Comparison of baseline characteristics of smokers and non-smokers}

Angiographic profile was not significantly different for smokers in terms of pre-procedural TIMI flow ( $\mathrm{p}=$ $0.373)$, number of vessels involved ( $p=0.813$ ), infarct-related artery ( $p=0.834)$, and LV dysfunction ( $p=$ 0.311). A comparison of the angiographic profile of smokers and non-smokers are presented in Table 2. 


\section{Cureus}

\begin{tabular}{|c|c|c|c|c|}
\hline Characteristics & Total & Smokers & Non-smokers & p-value \\
\hline Total & 580 & $297(55.2 \%)$ & $283(48.8 \%)$ & $\cdot$ \\
\hline Chronic total occlusion & $287(50.7 \%)$ & 156 (54\%) & $131(47.3 \%)$ & 0.078 \\
\hline \multicolumn{5}{|l|}{ Number of vessels involved } \\
\hline None & $1(0.2 \%)$ & $1(0.3 \%)$ & $0(0 \%)$ & \multirow{5}{*}{0.813} \\
\hline Single vessel (SVD) & $406(70 \%)$ & 206 (69.4\%) & $200(70.7 \%)$ & \\
\hline Two vessels (2VD) & $119(20.5 \%)$ & $61(20.5 \%)$ & $58(20.5 \%)$ & \\
\hline Three vessels (3VD) & $48(8.3 \%)$ & $25(8.4 \%)$ & $23(8.1 \%)$ & \\
\hline Left Main (LM) & $6(1 \%)$ & $4(1.3 \%)$ & $2(0.7 \%)$ & \\
\hline \multicolumn{5}{|l|}{ Infarct related artery } \\
\hline None & $11_{(0.2 \%)}$ & $11_{(0.3 \%)}$ & $0(0 \%)$ & \multirow{7}{*}{0.834} \\
\hline Left anterior descending (LAD) & $411(70.9 \%)$ & $211(71 \%)$ & $200(70.7 \%)$ & \\
\hline Right coronary (RCA) & $104(17.9 \%)$ & $56(18.9 \%)$ & $48(17 \%)$ & \\
\hline Left circumflex (LCX) & $52(9 \%)$ & $23(7.7 \%)$ & $29(10.2 \%)$ & \\
\hline Ramus & 3(0.5\%) & $11_{(0.3 \%)}$ & $2(0.7 \%)$ & \\
\hline Left main (LM) & $4(0.7 \%)$ & $2(0.7 \%)$ & $2(0.7 \%)$ & \\
\hline Diagonal & $5(0.9 \%)$ & $3(1 \%)$ & $2(0.7 \%)$ & \\
\hline \multicolumn{5}{|l|}{ Lesion complexity } \\
\hline None & $4(0.7 \%)$ & $1(0.3 \%)$ & $3(1.1 \%)$ & \multirow{6}{*}{0.595} \\
\hline A & $18(3.1 \%)$ & $12(4 \%)$ & $6(2.1 \%)$ & \\
\hline B & $116(20 \%)$ & $59(19.9 \%)$ & $57(20.1 \%)$ & \\
\hline c & $356(66.4 \%)$ & $178(59.9 \%)$ & $178(62.9 \%)$ & \\
\hline High C & $51(8.8 \%)$ & $29(9.8 \%)$ & $22(7.8 \%)$ & \\
\hline Non high C & $35(6 \%)$ & $18(6.1 \%)$ & $17(6 \%)$ & \\
\hline Side branch involvement & $68(11.7 \%)$ & $40(13.5 \%)$ & $28(9.9 \%)$ & 0.181 \\
\hline Left ventricular dysfunction & $328(56.6 \%)$ & $174(58.6 \%)$ & 154 (54.4\%) & 0.311 \\
\hline \multicolumn{5}{|l|}{ Thrombus grading } \\
\hline № & $43(7.4 \%)$ & $18(6.1 \%)$ & $25(8.8 \%)$ & \multirow{6}{*}{0.209} \\
\hline Possible & $42(7.2 \%)$ & $19(6.4 \%)$ & $23(8.1 \%)$ & \\
\hline Small & $61(10.5 \%)$ & $37(12.5 \%)$ & $24(8.5 \%)$ & \\
\hline Moderate & $109(18.8 \%)$ & $52(17.5 \%)$ & $57(20.1 \%)$ & \\
\hline Large & $85(14.7 \%)$ & $39(13.1 \%)$ & $46(16.3 \%)$ & \\
\hline Total & $240(41.4 \%)$ & $132(44.4 \%)$ & $108(38.2 \%)$ & \\
\hline
\end{tabular}

\section{TABLE 2: Comparison of the angiographic profile of smokers and non-smokers}




\section{Discussion}

The CAD in the young patient has altogether different manifestations due to the differences in clinical outcomes, presentation, and risk profile. CAD is no longer remains the old age disease, it is becoming more prevalent among the young population due to increased risk profile such as smoking, diabetes, and sedentary lifestyles $[8,14]$. In clinical practice, premature STEMI comprises of $2 \%-12 \%$ of the total STEMI $[8,14,15]$.

Among the other potential risk factors, such as unhealthy eating habits, obesity, and lack of physical activeness, smoking is the most prevalent risk factor [13]. A study conducted in our local population by Nadeem et al. [10] reported $46 \%$ current smokers among young ( $<45$ years) patients with a history of IHD. Various other studies in the past reported smoking as high as more than $80 \%$ in patients with premature myocardial infarction (MI) $[16,17]$. In our study, we found $51.2 \%$ smokers among young ( $\leqslant 40$ years) male patients presented with STEMI having no other cardiac risk factors such as diabetes, hypertension, dyslipidemia, and obesity.

Nicotine, carbon monoxide, and oxidant gases are the three basic constituents through which smoking deteriorates the cardiovascular system. The sympathomimetic effects of nicotine induce coronary artery vasoconstriction, leads to an increase in blood pressure, heart rate, and myocardial contractility [14,18]. Due to comparative more avid binding of carbon monoxide with hemoglobin, as compared to oxygen, it reduces the transportation of oxygen in the blood resulting in scarcity of oxygen within the heart [14,19,20]. Finally, the oxidant gases induce inflammation, cause endothelial damage, and increase plasma fibrinogen resulting in enhance coagulability. It also contributes to the thrombogenesis and platelet activation via oxidizing the LDL particles [19-21].

The smoker's paradox, an observational paradoxical phenomenon of favorable outcomes after AMI in smokers, is a common observation of various studies; however, there exists a controversy regarding smoker's paradox in young patients. Chen et al. concluded evidence to support the existence of a smoker's paradox in young ( $\leqslant 45$ years) patients, while, Liu et al. reported no paradoxical phenomenon in outcomes of AMI in young smokers $[9,22]$. It is important to address this phenomenon because it not only a clinical decision dilemma for clinicians, but also it is misleading for smoker patients [22]. In our study, we observed no significant differences in in-hospital outcomes of smokers and non-smokers patients, with no other conventional cardiac risk factor, suggesting no evidence of smoker's paradox in our young population.

To the best of our knowledge, this is the first study comparing the angiographic profile of young smokers and non-smokers, without any conventional cardiac risk factors, in our population. We found that male smokers and non-smokers had a similar clinical and angiographic profile in terms of KILLIP class at presentation, symptom onset to hospital arrival time, the extent of CAD, culprit vessel, lesion complexity, left ventricular function, and thrombus grading. Similarly, in-hospital outcomes such as post-procedure noreflow, acute stent thrombosis, and mortality were similar for smoker and non-smoker sub-groups. Our study findings are aligned with the finding of a systematic review and meta-analysis conducted by Liu et al. [9]. But persistent smoking after revascularization is an independent predictor of long-term reoccurrence of major adverse cardiac events (MACE) $[13,14]$. Therefore, emphasis on smoking cessation has a pivotal role in reducing the risk of MACE after AMI. In literature, the rate of smoking cessation after AMI varies from $28 \%$ to $77 \%$ depending on the definition of quitting and smoking [23-25]. In-hospital, as well as post-discharge smoking cessation counseling and programs should be part of every cardiac rehabilitation program. As quitting smoking is a complex and difficult process; therefore, effective interventions, both pharmacological and psychological, are the need of the time.

Our study has several limitations, the study was a retrospective study; therefore, the impact of quantum of smoking (number of packs or sticks) and the duration of smoking on outcomes could not be assessed. Secondly, due to the small sample size and single-center coverage, the finding of insignificant differences among smokers and non-smokers needs further confirmation in multicenter prospective studies with a larger sample size.

\section{Conclusions}

Our study concludes smoking has no significant impact on the angiographic profile and immediate clinical outcomes of primary PCI after STEMI in young males, without any other conventional cardiac risk factors. With these findings, further multicenter prospective studies are needed to identify other potential causes in such patients.

\section{Additional Information \\ Disclosures}

Human subjects: Consent was obtained by all participants in this study. National Institute of Cardiovascular Diseases Karachi issued approval ERC-33/2018. This study was approved by the institutional ethical review committee of the National Institute of Cardiovascular Diseases (NICVD), Karachi, Pakistan. 
Animal subjects: All authors have confirmed that this study did not involve animal subjects or tissue. Conflicts of interest: In compliance with the ICMJE uniform disclosure form, all authors declare the following: Payment/services info: All authors have declared that no financial support was received from any organization for the submitted work. Financial relationships: All authors have declared that they have no financial relationships at present or within the previous three years with any organizations that might have an interest in the submitted work. Other relationships: All authors have declared that there are no other relationships or activities that could appear to have influenced the submitted work.

\section{Acknowledgements}

The authors wish to acknowledge the support of the staff members of the Clinical Research Department of the National Institute of Cardiovascular Diseases (NICVD) Karachi, Pakistan.

\section{References}

1. Nishtar S: Prevention of coronary heart disease in south Asia . Lancet. 2002, 360:1015-1018. 10.1016/S01406736(02)11088-9

2. Hata J, Kiyohara Y: Epidemiology of stroke and coronary artery disease in Asia . Circ J. 2013, 77:1923-1932. 10.1253/circj.cj-13-0786

3. Okrainec K, Banerjee DK, Eisenberg MJ: Coronary artery disease in the developing world . Am Heart J. 2004, 148:7-15. 10.1016/j.ahj.2003.11.027

4. Popkin BM, Adair LS, Ng SW: Global nutrition transition and the pandemic of obesity in developing countries. Nutr Rev. 2012, 70:3-21. 10.1111/j.1753-4887.2011.00456.x

5. Reddy KS: Cardiovascular diseases in the developing countries: dimensions, determinants, dynamics and directions for public health action. Public Health Nutr. 2002, 5:231-237. 10.1079/phn2001298

6. Hossain P, Kawar B, El Nahas M: Obesity and diabetes in the developing world--a growing challenge . N Engl J Med. 2007, 356:213-215. 10.1056/NEJMp068177

7. Cardiovascular disease. (2019). Accessed: 1st April 2019: https://www.who.int/cardiovascular_diseases/en/.

8. Singh B, Singh A, Goyal A, et al.: The prevalence, clinical spectrum and the long term outcome of STsegment elevation myocardial infarction in young: a prospective observational study. Cardiovasc Revasc Med. 2019, 20:387-391. 10.1016/j.carrev.2018.07.020

9. Liu Y, Han T, Gao M, Wang J, Liu F, Zhou S, Chen Y: Clinical characteristics and prognosis of acute myocardial infarction in young smokers and non-smokers ( $\leqslant 45$ years): a systematic review and metaanalysis. Oncotarget. 2017, 8:81195-81203. 10.18632/oncotarget.21092

10. Nadeem M, Ahmed SS, Mansoor S, Farooq S: Risk factors for coronary heart disease in patients below 45 years of age. Pak J Med Sci. 2013, 29:91-96. 10.12669/pims.291.2828

11. Kirtane AJ, Kelly CR: Clearing the air on the" smoker's paradox" . J Am Coll Cardiol. 2015, 65:1116-1118. 10.1016/i.jacc.2015.01.012

12. Ashraf T, Afaque SM, Aziz R, et al.: Clinical, angiographic characteristics and in-hospital outcomes of smoker and nonsmoker patients after primary percutaneous coronary intervention. Global Heart. 2019, 14:335-341. 10.1016/j.gheart.2019.07.007

13. Rakowski T, Siudak Z, Dziewierz A, Dubiel JS, Dudek D: Impact of smoking status on outcome in patients with ST-segment elevation myocardial infarction treated with primary percutaneous coronary intervention. J Thromb Thrombolysis. 2012, 34:397-403. 10.1007/s11239-012-0764-0

14. Rallidis LS, Pavlakis G: The fundamental importance of smoking cessation in those with premature STsegment elevation acute myocardial infarction. Curr Opin Cardiol. 2016, 31:531-536. 10.1097/HCO.0000000000000320

15. Batra MK, Rizvi NH, Sial JA, Saghir T, Karim M: Angiographic characteristics and in hospital outcome of young patients, age up to 40 versus more than 40 years undergoing primary percutaneous coronary intervention. J Pak Med Assoc. 2019, 69:1308-1312.

16. Schoenenberger AW, Radovanovic D, Stauffer JC, et al.: Acute coronary syndromes in young patients: presentation, treatment and outcome. Int J Cardiol. 2011, 148:300-304. 10.1016/j.ijcard.2009.11.009

17. Puricel SG, Lehner C, Oberhänsli M, et al.: Acute coronary syndrome in patients younger than 30 years-aetiologies, baseline characteristics and long-term clinical outcome. Swiss Med Wkly. 2013, 143:w13816. 10.4414/smw.2013.13816

18. Czernin J, Waldherr C: Cigarette smoking and coronary blood flow . Prog Cardiovasc Dis. 2003, 45:395-404. 10.1053/pcad.2003.00104

19. Messner B, Bernhard D: Smoking and cardiovascular disease: mechanisms of endothelial dysfunction and early atherogenesis. Arterioscler Thromb Vasc Biol. 2014, 34:509-515. 10.1161/ATVBAHA.113.300156

20. Siasos G, Tsigkou V, Kokkou E, et al.: Smoking and atherosclerosis: mechanisms of disease and new therapeutic approaches. Curr Med Chem. 2014, 21:3936-3948. 10.2174/092986732134141015161539

21. Barua RS, Ambrose JA: Mechanisms of coronary thrombosis in cigarette smoke exposure. Arterioscler Thromb Vasc Biol. 2013, 33:1460-1467. 10.1161/ATVBAHA.112.300154

22. Chen KY, Rha SW, Li YJ, et al.: 'Smoker's paradox'in young patients with acute myocardial infarction. Clin Exp Pharmacol Physiol. 2012, 39:630-635. 10.1111/j.1440-1681.2012.05721.x

23. Rallidis LS, Sakadakis EA, Tympas K, Varounis C, Zolindaki M, Dagres N, Lekakis J: The impact of smoking on long-term outcome of patients with premature ( $\leqslant 35$ years) ST-segment elevation acute myocardial infarction. Am Heart J. 2015, 169:356-362. 10.1016/j.ahj.2014.12.003

24. Rallidis LS, Hamodraka ES, Foulidis VO, Pavlakis GP: Persistent smokers after myocardial infarction: a group that requires special attention. Int J Cardiol. 2005, 100:241-245. 10.1016/j.ijcard.2004.08.040

25. van Berkel TF, Boersma H, Roos-Hesselink JW, Erdman RA, Simoons ML: Impact of smoking cessation and smoking interventions in patients with coronary heart disease. Eur Heart J. 1999, 20:1773-1782. 10.1053/euhj.1999.1658 